\title{
SKYWAYS: A STRATEGY TO HUMANIZE THE MOBILITY OF THE VERTICAL CITIES
}

\author{
ADRIÁN MARTÍNEZ-MUÑOZ \\ Department of History, Theory and Architectural Composition, University of Seville, Spain
}

\begin{abstract}
The lack of contemporary theoretical support for the construction of the vertical city leads to the application of an inherited model, conceived almost a century ago. Therefore, the urban space suffers a strong dehumanization, disconnecting the inhabitants from the urban context. In the search for strategies to make the high-rise city of the coming decades more humane, it is worth proposing the hypothesis of a hyperconnected, three-dimensional and multi-layered vertical city: a mesh of pedestrian skyways between skyscrapers that reproduce streets and urban squares where citizens can socialize. This paper proposes a rereading of those experiences and projects that, from the beginning of the 20th century to the present, built or unrealized, contributed to elaborating a new ideology about elevated pedestrian mobility. These ideas elevated the social and the relational, away from ground level through skyways to find growth strategies at the human scale, and so declaring the age of the multilevel city. Keywords: pedestrian mobility, human scale, multilevel city, skybridges, skyways, vertical city
\end{abstract}

\section{INTRODUCTION}

Hundreds of vertical developments, with the residential tower typology as the cornerstone, spread throughout the main megalopolitan concentrations, especially in the Asia-Pacific region. The rapid urbanization of cities prevents a deep reflection on the appropriate model to follow. Planners, overtaken by a rising real estate market and political pressure, continue with the modern idea of converting quantity - overpopulation - into quality through abstraction and repetition: residential mega blocks distributed and repeated relentlessly over the territory.

At this massive scale, the hypothesis of a hyperconnected, three-dimensional and multilayered city could be offered as a way to rethink the vertical city, with the goal of humanizing the urban model. This hypothesis is also a reflection on mobility where the concept of walkability is re-evaluated regardless of verticality and seen as a powerful tool to create a more livable and sustainable city. Skyways, as bridges between skyscrapers dedicated to pedestrians, can play a fundamental role in the quality of the urban environment.

This paper studies the urban phenomenon of skyways in three steps. Firstly, the text succinctly examines the history of the multilevel city with the focus on elevated pedestrian systems. Secondly, a group of skyways, which are situated in real contexts, will be analysed. Finally, one experience and three projects from the architectural discipline will be reviewed to discover some strategies about mobility close to the clouds. The Journal of Transport Development and Integration has been selected because it involves the field of research closest to our subject of investigation. Although the concepts of sustainability, city planning and human comfort are closely related to the subject of this paper, it is within the field that deals with the integration of the different forms of mobility and their harmonization in the city, where the debate could find a better audience. 


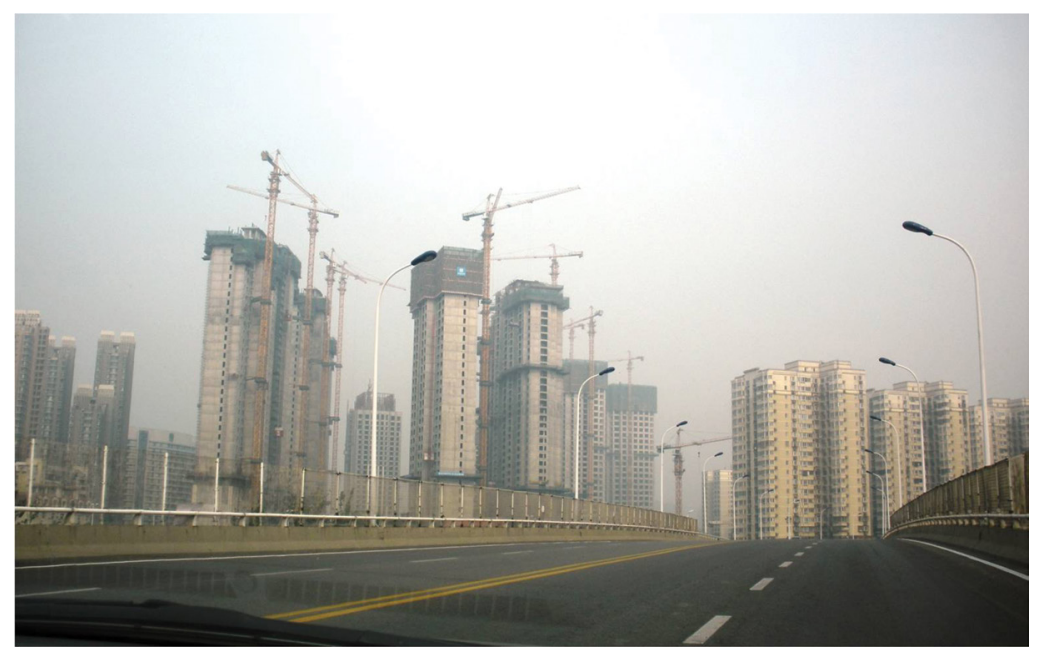

Figure 1: Tianjin, China (picture by the author).

\section{METHODOLOGY}

In order to provide a new strategy to challenge the vertical city based on modern principles and achieve models which could generate a more humane city from the mobility perspective, this paper establishes a methodology based on some conceptual developments and projects. These projects, primarily from the twentieth century, were based on a mesh of skyways and proposed to elevate pedestrian mobility as a duplication of the ground level.

Firstly, a survey of the history of architecture was done, particularly in search of projects and case studies produced by other architects who worked with the idea of radically introducing a fragment of urban space at a certain height: skyways, skywalks, pedways and footbridges. Also, an initial study of existing peer-reviewed journal papers, historical archives, news articles, existing performance data on vertical transportation, etc., was carried out.

Secondly, after the initial selection, fundamentally from the 20th century to the present, these projects and examples were ordered and categorized. In addition, the author has participated in international workshops and seminars on the subject. Interviews and feedback from these encounters have been incorporated into the overall research.

Thirdly, a critical analysis and comparison using a systematic set of principles and criteria between the projects of the same 'category' was done, with the target of defining a new way to rethink the vertical city.

\section{A BRIEF HISTORY OF THE MULTILEVEL CITY}

The publisher Moses King, driven by the ambition to predict the city to come and the hectic pace of the laissez-faire building of New York, published in 1896 the first edition of his King's Views of New York guide series. In this and subsequent editions, King recorded through photographs and drawings the rapid change that the island of Manhattan was undergoing. The covers that illustrated the 1908 King's Dream of New York and the 1911 King's Views of New York editions, which were commissioned from two architects, Harry M. Pettit and Richard Rummell respectively, deserve special attention.

Both frontispieces were inspired by problems that were beginning to condition Manhattan at the beginning of the century, such as the impact that skyscrapers and increased vehicular 
traffic had on the ground, and therefore, on pedestrians. The cover drawn by Pettit, titled The Cosmopolis of the Future (Fig. 2), answered the commission with a futuristic vision of tiered skyscrapers plus a multilevel circulation system. On the one hand, the terraced skyscraper was drawn as a way to bring light and air to the lower levels of the congested streets of New York, and on the other hand, a multilevel mobility network was imagined as an efficient tool to organize a large number of vehicles and people that flooded the city every day. Although separated by only three years, the worlds portrayed in both illustrations showed certain differences. In 1908 Pettit, despite a sky overcrowded by huge aeroplanes, revealed an urban world dominated by pedestrians crowding skyways and elevated bridges. The 1911 cover titled The Future of New York is Pre-eminently the City of Skyscrapers (Fig. 2), drawn by Rummell, portrayed a city dominated by machines: extensive rail networks on bridges instead of pedestrians, streetcars, and automobiles on the ground floors. Even the setbacks (terraces and balconies) were emptied of inhabitants to give all the prominence to the mechanization of the urban space that so excited thinkers at the beginning of the century.

The illustrators who accompanied Moses King were not the only ones who envisioned a future city spread out in space. In the same year as the Harry M. Pettit image, another artist composed the cover that opened Man's Machine-Made Millennium (Fig. 2), published by chemist and inventor Hudson Maxim in Cosmopolitan magazine in its November 1908 issue. The visionary illustration, carried out by the successful American artist William Robinson Leigh, showed a great city as a huge building. A kind of spatial framework, massive at times, with infinite bridges that jumped in all directions over the deep avenues: some loaded with pedestrians, others like traffic routes that pierced the built mass of the enormous buildings.

The now-defunct New York Tribune newspaper, in its print run on Sunday, January 16, 1910, published a full-page drawing that returned to the three-dimensional city in several layers and levels. Inside the newspaper, a column titled Sees future New York: Sidewalks in layers and other wonders in Mr. Suplee's Ken (Fig. 3) could be read. Strangely, three years later, the same lightly tweaked drawing appeared in the weekly Scientific American in late July, illustrating The Elevated Sidewalk: How it will solve City Transportation Problems (Fig. 3)
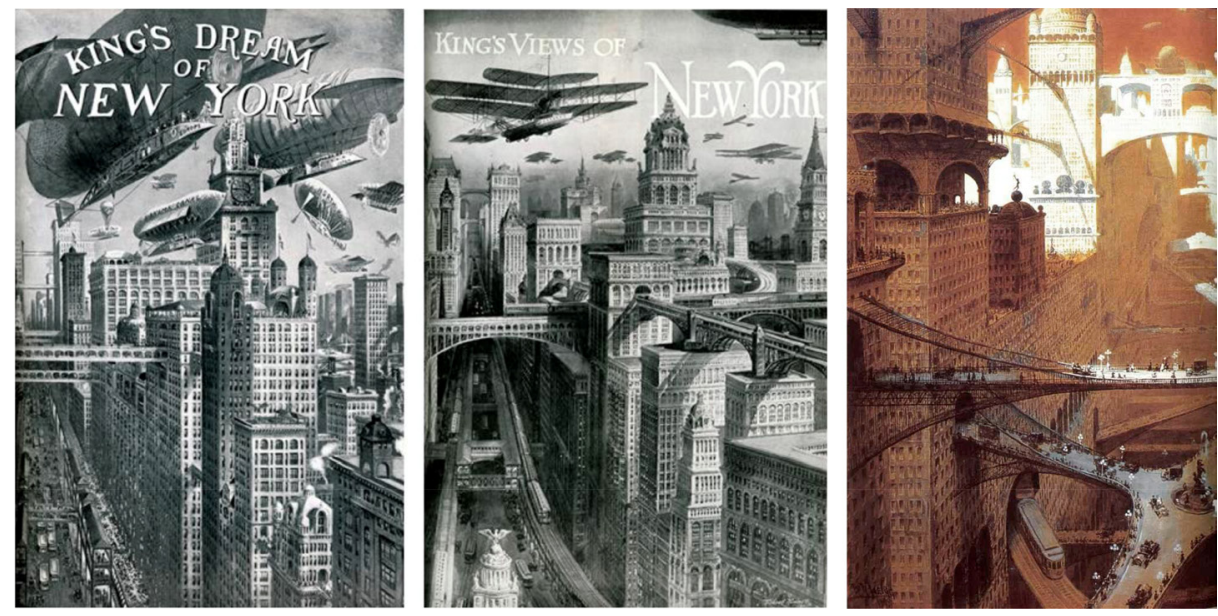

Figure 2: (A) 'King's Dream of New York' by H. M. Pettit in 1908 [1]; (B) 'King's Views of New York' by R. Rummell in 1911 [2]; (C) Drawing by W. R. Leigh, 1908 [3]. 


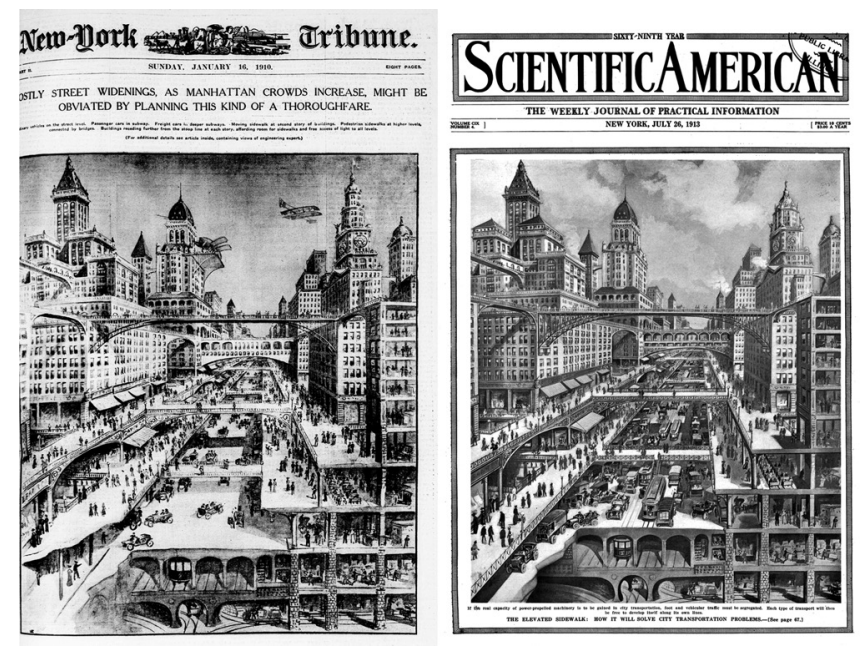

Figure 3: (A) Newspaper New York Tribune 16th January 1910 [4]; (B) Scientific American magazine 26th July 1913 [5].

by engineer Henry Harrison Suplee, apparently the same author from the New York Tribune article. The main difference between these almost twin images was centred on the accumulation of traffic on the ground floor. Once the city had been organized on different levels, with pedestrians roaming freely on the upper sidewalks, the biggest advance focused on transportation. While the 1910 cover showed cars winding freely, the 1913 cover presented a tram in the centre that separated the large avenue in two.

In 1929, the New York Regional Plan asked various experts for proposals to solve the congestion which was blocking Manhattan. Harvey Wiley Corbett, a prominent architect and professor at Columbia University, presented an ambitious plan for the separation of vehicular and pedestrian traffic, largely based on reformulations of his earlier studies from 1923 of the city at various levels. The proposal, developed with the perspectivist Hugh Ferriss (Fig. 4), was conceived as a multilevel city with several infrastructures for traffic and pedestrian in all directions. Skyscrapers of this imagined city were connected in a continuous skyway. The proposal was a kind of highly modernized Venice in which the canals were flooded by vehicles instead of water, solving congenital congestion through shock therapy: multiplying traffic.

At other side of the Atlantic, even though Italian futurists and Russian constructivists produced a certain machinist iconography concerning buildings and cities connected at certain heights, the chronicle of the European reaction to the typology born overseas pointed to Le Corbusier's urban approaches. His Contemporary City for Three Million Inhabitants exhibited at the Salon d'Automne in 1922, planted the seed of the principles that defined the Corbusian ideals against the problems of the nineteenth-century city: an urban architecture of 'air, vegetation, sun and the car'. A Cartesian city composed of cruciform skyscrapers that, devoid of any singularity, became the isotropic and mechanical element that infinitely dotted the territory. The City Towers (1922), by August Perret, was a model that Le Corbusier surely had in mind while he projected his idea of the city. However, he eliminated from Perret's project the element that most interests this paper: the skybridges that linked the towers. He did so because he considered them dangerous. 


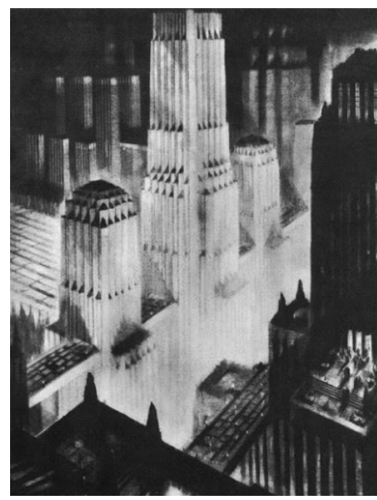

Figure 4: Hugh Ferriss. The Metropolis of Tomorrow, 1929 [6].
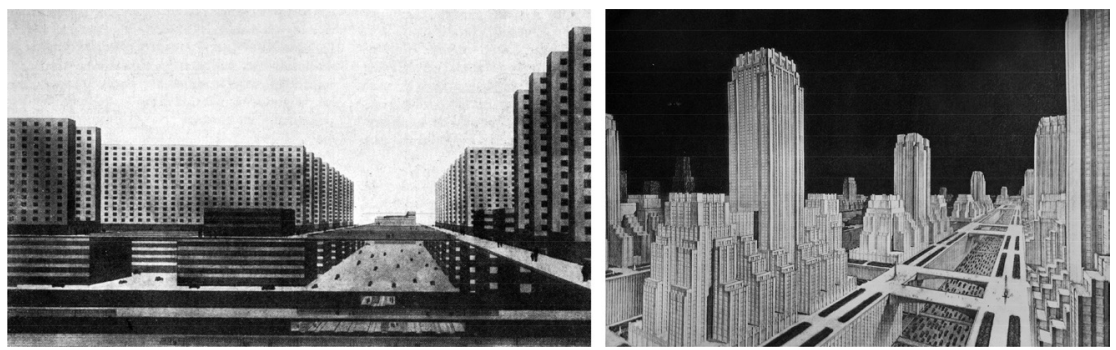

Figure 5: (A) Ludwig Hilberseimer. Vertical City, 1924 [7] and (B) Francisco Mújica. The City of the Future: Hundred Story City in Neo-American Style, 1929 [8].

Hilberseimer projected his model of the city in parallel to Le Corbusier, surely more in tune with what was taking place on the other side of the ocean. In 1924 he presented a city approach based on the section, on the stacking of uses, instead of the Corbusian horizontal zoning. The project, known as Vertical City or Hochhausstadt (Fig. 5), proposed a dense and three-dimensional city, both in terms of uses and mobility, taking advantage of the natural overlap of the skyscraper typology. In his spatial model, traffic had three dimensions, attributing the third dimension to the displacement that would occur between the residential city and the commercial city, the first located above the second. Mobility was separated into several planes, similar to the American illustrations discussed above, which allocated the lowest level for vehicles and set a new zero level for the development of life in the plane shared by the residential and commercial city. A rigid network of bridges outlined that pedestrian plane, providing what Le Corbusier decided not to incorporate into his urban imagery.

Hilberseimer's images of the city seemed to find a replica in the drawings that the Mexican architect Francisco Mújica, fascinated by the city of skyscrapers and in tune with Corbett's postulates, made after his trip to New York in 1926. Beyond the conviction that it had on the construction of the metropolis with pyramidal typologies close to the preHispanic temples, his drawing showed a city built on two well-differentiated levels: the lower one for road traffic and the upper one for pedestrians. The rigidity and orthogonality 
of his city zoned by height, entitled The City of the Future: One Hundred Story City in NeoAmerican Style (Fig. 5) and published in his only book The History of the Skyscraper in 1929, is reminiscent of that Hilberseimerian Hochhausstadt.

However, the most influential review of the spatial organization of mobility in a real vertical city context emerged, a decade after Hilberseimer's cited work, with the construction of Rockefeller Center in Manhattan between 1931 and 1939. The dense network generated there, intertwining different programs at various levels, would once again mark the architectural debate just at the time when the Charter of Athens was being drafted.

\section{SKYWAYS IN REAL CONTEXT}

Known as a 'city within a city', the Rockefeller Center (Fig. 6) was conceived as a reduced model of Manhattan itself in the middle of the Great Depression. The network of streets, by way of underground galleries, began a new way of understanding the city that unfolded below ground level, linking car parks, train stations, metro, offices, shops and squares in an exceptional complexity. It was the first time that a continuous pedestrian system was articulated between different volumes and users, generating a structure that increased the relationship with its urban context. Never before a network of 'public tunnels' had sewn together several blocks, resulting in a unitary fragment of the city within the city itself, in perfect harmony with it.

Although the Rockefeller Center network, completed at the beginning of the World War II, failed to alter the destiny of cities, it generated such astonishment that in the years after the war, commercial networks began to emerge between skyscrapers throughout the American continent. Even though the Rockefeller network was developed underground, the concept could perfectly be transferred to an elevated level as a group of skyways. In fact, in 1956, a group of young architects influenced by Victor Gruen's multilevel urbanism teachings proposed a network of high-rise pedestrian streets that was implemented in downtown St. Paul, the second largest city in the state of Minnesota. A year later, the architects of the University of Minnesota presented a similar plan for the centre of Minneapolis (Fig. 6), a neighbouring city.

Separated by the Mississippi River, networks such as the elevated streets of Minneapolis and St. Paul differ fundamentally in the character of their management: private in the first case, public in the second one. The fabric of Minneapolis was built piecemeal through tradeoriented private investors. The first two bridges were built in 1962; later, the great Nicollet Mall increased the network in 1968; in the 1970s, with Philip Johnson's IDS Center project (1972) (Fig. 6), much of the elevated street network was consolidated.
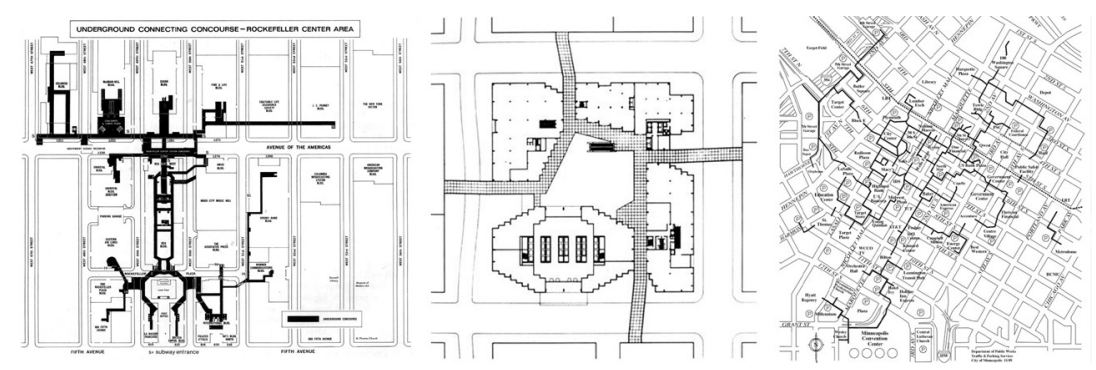

Figure 6: (A) Rockefeller Centre New York, 1939 [9]; (B) P. Johnson and J. Burgee. IDS Center, Minneapolis, 1972 [10]; (C) Skywalks downtown Minneapolis [11]. 
Today, the experience of Minneapolis, with more than $18 \mathrm{~km}$ of elevated streets (the longest in the world), has become a system on which investors depend if they want to succeed with their new skyscrapers. When a new skyscraper is planned in Minneapolis, the first issue to take into account is the connection with the network of skyways, with the target of getting the necessary flux of pedestrian, especially in the colder months when it is impossible to walk outside.

The cases of Minneapolis and St. Paul were not the only ones that emerged in the American continent during those years. In Calgary (Canada), conceived by the architect Harold Hanen, another network of air-conditioned elevated streets that crossed skyscrapers was projected; this time as a unique project from the beginning of its creation. It was known as Plus 15 since generally the bridges that crossed the towers were located at 15 feet, about 4.5 meters above the city ground floor. This plot connected several dozen buildings, including the most important shopping centres and shops in the downtown. The Calgary case was not a specific experience applied to a fragment of the city. On the contrary, it aspired to become a prototype of a vertical city where the network of elevated streets completed the total extension of the urban area.

Throughout 1969, the still futuristic relationship between vehicular traffic and pedestrian traffic at an elevated level, appeared again in New York, with the recovery of the Second Regional Plan. This plan happened forty years after, and as a sequel to that of 1929. Under the title Urban Design Manhattan, and compiled by Rai Okamoto and Frank Williams, the second part of the Regional Plan concentrated its major advances in the identification of nodes scattered around the city where hybrid multi-level districts should be located as centres within the great centre: Grand Central Station, Times Square, Columbus Circle and Rockefeller Center, among others. This reformulation of the mobility and urbanism of the New York fabric culminated in the proposal of a new Office Cluster Model (Fig. 7), as one more node of the polycentric matrix, in the Greenwich Village area, west of midtown. This vertical complex condensed a group of office towers, with dwellings on the upper levels, crossed every ten floors by pedestrian bridges that provided some freedom of vertical and horizontal movement. The mobility system, through the access tree principle, added an extraordinary spatial complexity, without thereby impeding the correct functioning of road traffic at ground level. The efficient three-dimensional infrastructure, with a capacity for 120,000 workers, was in part indebted to the ideas defended years before by Stanley Tankel, in collaboration with Jane Jacobs, against the urbanism of Robert Moses. The main target of the Second Regional Plan of New York was not only to accommodate the high growth of population and propose a solution to the problem of traffic congestion of the metropolis, but also, to keep the scale and lifestyle of New York neighbourhoods such as Village, where Jane Jacobs lived.

On the other side of the world, in Hong Kong (Fig. 7), one of the densest cities and with the greatest scarcity of ground on the planet, we can witness a labyrinthine three-dimensional landscape of elevated public roads drawn by the different daily flows: skywalks, underground passages, escalators and elevators. In the city of Hong Kong, there is not a conventional relationship between the levels of mobility, in part, forced by the sharp topography that acts as a background, and in part by the high population density. Hong Kong is today a city without ground - or with many overlapping grounds - in which one can move from one end of the city to the other without stepping on the ground established as ground zero. Elevated walkway systems now span the majority of the Sheung Wan, Central, Admiralty, and Wan Chai districts. The pedestrian network features a range of connector prototypes, including deckaccess plazas and podiums, flyover bridges, open-air footbridges, and high-bridge networks 

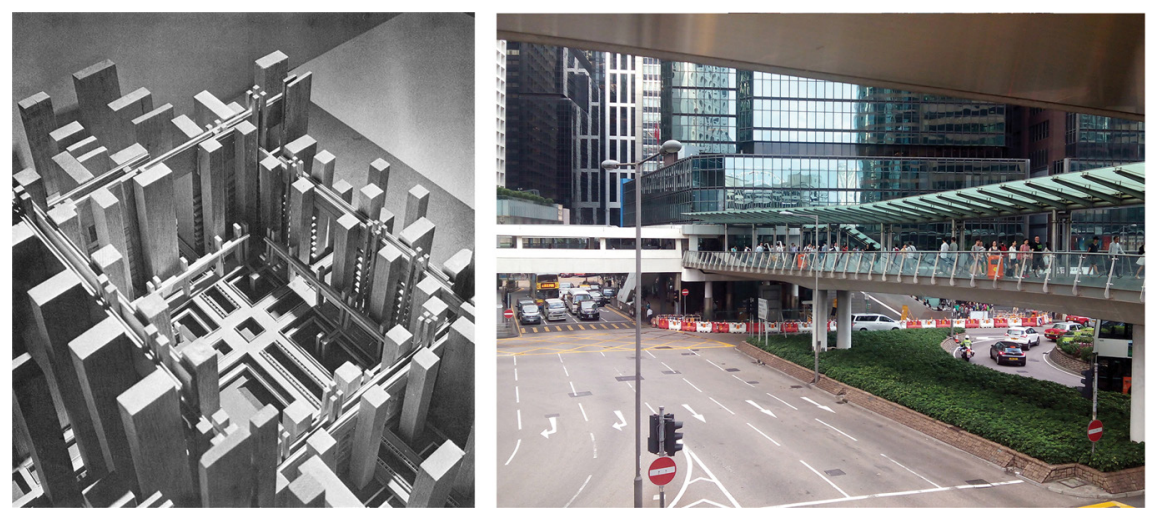

Figure 7: (A) Second New York Regional Plan, 1969 [13]; (B) Hong Kong Skywalks (Picture by the author).

(exterior pedestrian bridges over streets), interiorized walkways, elevated parks, and exterior escalators that scale the steep hillsides. In the book Cities without ground: a Hong Kong guidebook, authors write: 'Urbanism in Hong Kong is a result of a combination of top-down planning and bottom-up solutions, a unique collaboration between pragmatic thinking and comprehensive masterplanning, played out in three-dimensional space. Footbridge networks throughout the city that grew piecemeal, built by different parties at different times to serve different immediate needs, eventually formed an extensive network and became a prevailing development model for the city's large-scale urban projects' [12].

Although the case of the High Line in New York was born with a different purpose than the aforementioned networks, it could be cited in this paper as a case that, from the contemporary vertical city point of view, proposes a linear infrastructure as an elevated urban park with great social success. The project repurposed the old and abandoned West Side Line of the railroad to transform it into almost $2.5 \mathrm{~km}$ of the landscaped promenade, stretching from the Meatpacking neighbourhood to the Hudson Rail Yards in Manhattan. In its linear development, it encompasses everything from stands for improvised shows, small squares and living areas to spaces for the exhibition of large-scale sculptures. The warp of the High Line, weaving together several skyscrapers at a certain height, is used by hundreds of New Yorkers every day to cross the west of the island from 30th Street to Gansevoort Street. Even though the project has a clear public vocation, like the rest of the streets and squares in the metropolis, it suffers from a strict time access restriction, probably due to security problems. If the High Line had been a real public infrastructure, open 24/7, we would have analysed it as a true skyway that helps humanize the vertical city.

\section{FOUR CASE STUDIES WHERE MOBILITY IS DEVELOPED SEVERAL METERS ABOVE THE GROUND}

\subsection{Steven Holl, The Linked Hybrid, Beijing (China), 2009}

With a kaleidoscopic dimension of 'city within a city', like that slogan that accompanied the Rockefeller Center, the Linked Hybrid project (Fig. 8) could well belong to a fragment of the aerial frameworks of Minneapolis, Calgary or Hong Kong. In the diagrams that explain 


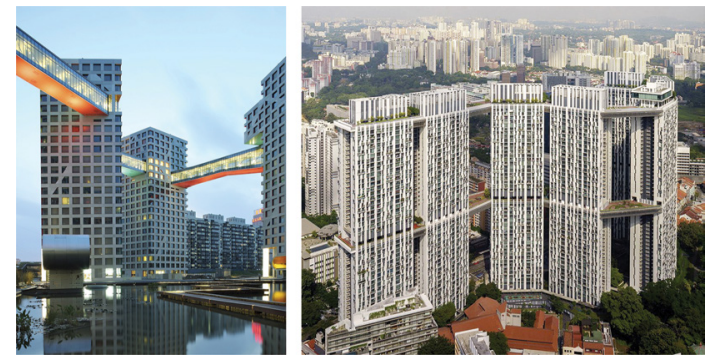

Figure 8: (A) Steven Holl, The Linked Hybrid, 2009 [14]; (B) ARC+RSP, The Pinnacle Duxton, Singapore, 2009 [15].

the gestation of the project, the city model that Steven Holl tried to make us understand was concentrated. It consisted of three small skylines of cities: the first showed a horizontal city of small buildings until 1980, the second exhibited a city of isolated and repeated monofunctional towers from 1980 and finally, the third (the Holl's proposal) was drawn as a city of hybrid skyscrapers connected by skyways as a multilevel city. And this is the most interesting idea for this research: the elevated street that links the eight towers. The elevated street, with a variable width between five and fifteen meters, began at level twelve of the hotel tower at one end, and reached level eighteen on its way to the tower that encloses the site, leaving the ring unfinished. Holl placed program in these glass bridges or skybridges, including a gym, an art gallery, cafeterias, and even a swimming pool, with the added complexities that this implied structurally. The complex was intended to be a fragment of a self-sufficient city, hybridizing all kinds of uses between the volumes of the ground floors and the high street as a pedestrian system. Linked Hybrid thus housed a population of 2,500 inhabitants, aspiring to become an avant-garde prototype of the urban lifestyles of the 21 st century.

\subsection{ARC+RSP, The Pinnacle Duxton, Singapore, 2009}

The City of Singapore is a pioneer in this kind of projects, among which is The Pinnacle Duxton (Fig. 8), built by ARC + RSP Architects in 2009. A vertical complex of 1,848 houses and 50 floors high that dreams of literally bringing the street and the plaza to the clouds, producing elevations of urban strata several meters from the Earth's mass to create a multiground zero city. At The Pinnacle Duxton, the two trays aspire to reproduce outdoor spaces according to the tropical climate of Singapore: gardens for children's games, spaces for barbecues, solariums, areas equipped for gymnastics and a running route of $800 \mathrm{~m}$ in length, among others. Singapore is an architectural lab of this kind of buildings where a group of skyways offer public spaces in tallness, transferring squares and streets beyond the zero level. Between the most highlighted projects are The Interlace (2013) by OMA, SkyVille (2015) by WOHA architects or Sky Habitat (2016) by Safdie architects.

\subsection{Chongqing city, China}

In search of those public circuits that intrude between towers, I found, during the summer of 2019, in The Guardian newspaper, within its Cities section, a review entitled Humans vs the city: the staggering scale of Chongqing in pictures (Fig. 9). The article showed an urban 


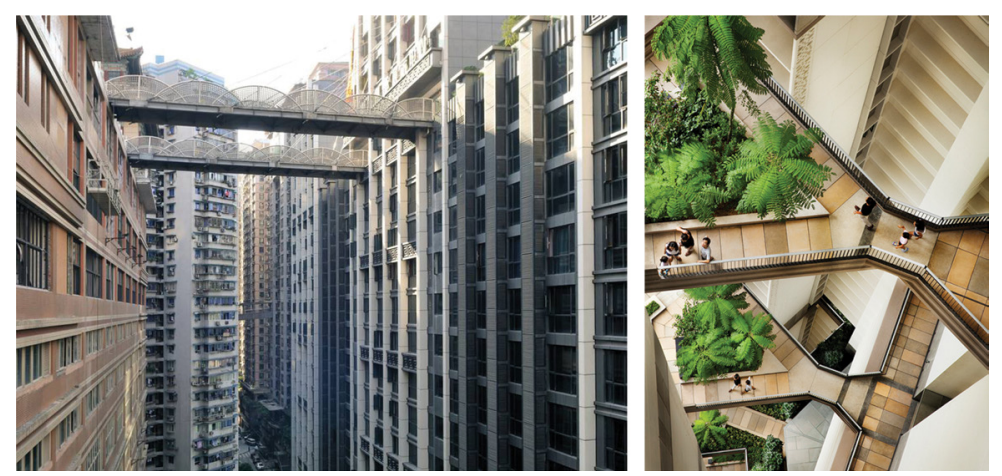

Figure 9: (A) Skybridges in Chongqing, China, 2019 [16]; (B) WOHA, Skyville Dawson, Singapore, 2015 [17].

landscape of a Chinese megacity where some pedestrian skyways, subway lines and railways interceded in tallness among towers that make up the city. It was Chongqing, the city that exercises control over the Three Gorges area of the Yangtze River, one of the densest and most developed urban concentrations in the centre of China. When contemplating the aerial photos of this city, one perceives a certain overflow of urbanism; a high concentration of almost identical towers that obscure the sky and hide the horizon. What is unusual, which distinguishes some neighbourhoods in this city from many others in the same country, is the existence of an elevated network of streets, promenades, rails and even cable cars. Unlike the model of towers planted on a plane in which the only point of contact with the city occurs in the lobby on the ground floor, various aerial streets in several districts of Chongqing cross residential, commercial, mega blocks offices, regardless of their nature or use, to shorten roads and detach themselves from the ground-level.

\subsection{WOHA, Skyville Dawson, Singapore, 2015}

As we have analysed in the case of The Pinnacle Duxton, Skyville Dawson building, by the Singapore office WOHA, is a conglomerate of 960 houses in an existing neighbourhood in the south of the city (Fig. 9). The concept of the project is the result of six residential towers that through different orientations and turns generate empty spaces between them. It is those spaces between the towers where the pedestrian walkways are located every eleven floors that serve as public spaces and relationships for the inhabitants of the complex. These skybridges, fed by the main communication centres, reproduce squares and streets of the existing city a few meters below. From large communal terraces to gardens, this project is an example of how to multiply the ground level in height, elevating the public space and alleviating any potential congestion. While walking to and from each apartment, residents are treated to a view of the garden terrace below and various communal living spaces throughout the complex.

\section{RESULTS AND DISCUSSION}

Once these references and cases studies have been described, this chapter discusses the benefits and drawbacks that make these meshes of skyways an opportunity to improve the social life and the quality of the public spaces in the context of vertical cities. From the beginning of the twentieth century, when cars arrived massively to the cities, architects and urban planners were aware of the necessity to rethink mobility. Two points of view have been contrasted in 
this paper, Corbusier's perspective with a two-dimensional city and the multilevel city as a three-dimensional urban landscape. Within the multilevel city, theoretical proposals have been named, such as Corbett and Ferris, or the late work of Hilberseimer and Mujica, in which it is easily appreciable the separation of pedestrian level and vehicular traffic.

The transformation of the urban scale, making the city ever taller, denser and faster, increases the difficulty of social participation in the urban context [18]. This harsh dehumanization leads inhabitants to exclusion from city life, leaving them disconnected several meters above the ground. With this complex problem to solve in our contemporary vertical cities, it seems that the introduction of skyways in height as a mesh of public space dedicated to the pedestrian can offer a more participatory urban model and where the sense of community becomes an important point in the urban planning. When skyways are projected from the beginning as a master plan, the level of success is more noticeable than when it is just a fragment in an isolated building. In this sense, this paper has analysed the networks of Minneapolis, Calgary, or Hong Kong, among others, as a system for pedestrian mobility that involves the city completely: cities where pedestrians can move from one extreme to the other without walking on the ground floor. This group of linear elevated skyways with different entry points reacts to the concept of walkability, offering pedestrians mobility without obstacles and with a new top view of the city.

However, this form of urbanism as a multilevel microcosm in which pedestrians are remotely controlled by mass consumer networks has been subjected to significant criticism in recent times [19]. It seems that walking becomes part of the chain of production and consumption in a mechanical act. 'The movement of people in space has become a controlled, repeated and risk-free activity,' wrote Richard Sennet [20]. The solution must find a dynamic balance between the public realm and capitalist logic: a fair proportion in the programs that accompany these skywalks, threading the network with residential towers and feeding the network of public spaces for socialization, far from a purely commercial circuit.

On the other hand, there is a certain risk of isolation and disconnection of those streets in the air if they are designed as privileged bunkers for select elites. In the projects Linked Hybrid, The Pinnacle Duxton and Skyville Dawson, the network of skyways is closed to the social life of the city they belong to. In the light of the results, these projects will acquire relevance if the now isolated street extends to weave a good part of the towers that build the city vertically, leaving the network open for future growth. When the aerial frameworks belong to an isolated construction within a plot, they are susceptible to failure, and therefore it would be a primary appreciation for that network to be deployed from the current zero levels, calibrating uphill slopes so that the elevated street becomes that intermediate space that is both on the way to the house and to the city. This would constitute a plan that would challenge the current management of land ownership, evolving from a two-dimensional administration to a threedimensional one, from plan to volume.

\section{CONCLUSION}

The study concludes that those 'urban meshes', made of skyways, can became an alternative to pedestrian mobility in vertical cities if they are conceived as a total urban design, instead of as an isolated intervention in a group of skyscrapers. Another concept that we will have to rethink in the near future is the slow mobility, which in general is related with the pedestrian. Rapid urbanization, as well as the evolution of the high-rise building, followed by an increase of automobile use, requires the development of more walkable public spaces for people: 'For walkable spaces to be used for a wide range of spontaneous activities, like leisure, recreation, market, informal sport and dance, performance, etc.' [21]. A strategy based on elevated paths, 
where people can find a scale more adapted to them, would produce a more sustainable and more livable environment, and, more importantly, a more humane city.

According to current United Nations (UN) projections, by the year 2050 the world population will increase from 7.6 billion to 9.7 billion and close to $66 \%$ of the population will live in cities, declaring the age of the vertical city. So, what if it was not possible to reject the construction of the vertical city? [22].

\section{ACKNOWLEDGEMENTS}

The author would like to recognize the generous help of VI Plan Propio de Investigación y Transferencia 2020 of the University of Seville. Also, this project is funded in part by the Education Ministry of Spain with a FPU scholarship, which I acknowledge with great thanks.

\section{REFERENCES}

[1] King, M., King's Views of New York 1896-1915, New York: Arno Press, 1977.

[2] King, M., King's Views of New York, New York: The Charles Francis Press, 1912.

[3] Hudson, M., Man's Machine-Made Millennium. Cosmopolitan Magazine, XLV(6), pp. 560-576. Harvard University Collection, 1908.

[4] Suplee, H., Sees future New York. Sidewalks in layers and other wonders in Mr. Suplee's Ken, New York Tribune, cover, 1910.

[5] Suplee, H., The elevated sidewalk: how it will solve city transportation problems. Scientific American, 109(4), 1913. Cover of the magazine.

[6] Ferriss, H., The Metropolis of Tomorrow. New York: Ives Washburn, 1929.

[7] Hilberseimer, L., La arquitectura de la gran ciudad. Barcelona: Gustavo Gili, 1979.

[8] Mujica, F., History of the Skyscraper. Paris: Archaeology \& Architecture, 1929.

[9] Frampton, K., The Generic Street as a Continuous Built Form. On Streets. Cambridge, MA: MIT Press, 1978, p. 334.

[10] Miller, N., Johnson \& Burgee: Architecture. New York: Random House, p. 30, 1979.

[11] Department of Public Works Traffic \& Parking Services City of Minneapolis.

[12] Frampton, A., Solomon, J., Wong, C., Cities Without Ground. San Francisco: ORO Editions, p. 6, 2012.

[13] Okamoto, R., Williams, F., Urban Design Manhattan: Regional Plan Association. New York: The Viking Press, p. 100, 1969.

[14] Steven Holl website (https://www .stevenholl.com/projects/beijing-linked-hybrid)

[15] ARC Studio Architecture + Urbanism (http://arcstudio.com.sg/)

[16] Yan, G., Pedestrian bridges run through residential high-rise in Chongqing. China: China Plus, 2017. (http://chinaplus.cri.cn/photo/china/18/20170605/5835.html)

[17] WOHA website (https://woha.net/project/skyville-dawson/)

[18] Martínez-Muñoz, A., From the high-rise housing block to the megastructure in the air. A critical reflection on the contemporary vertical city. RITA $\mathrm{n}^{\circ} 13$, Madrid: Red fundamentos S.L., 2020.

[19] Cuthbert, A.R, Mckinnell, K., Ambiguous space, ambiguous rights - corporate power and social control in Hong Kong. Cities, 14(5), pp. 295-312, 1997.

[20] Sennett, R., The Fall of Public Man. New York: W.W. Norton, 1992.

[21] Wang, L., et al. Walkable Cities in High Density China, Shanghai: Tongji University Press, 2017.

[22] Martínez-Muñoz, A., Humanizing the Vertical City: Three strategies to bring the ground level closer to the clouds. WIT Transactions on Ecology and the Environment, 249, WIT Press, pp. 57-69, 2020. 